\title{
Implementation of antithrombotic management in atrial fibrillation
}

\author{
S J McNulty, D Hutchinson, K J Hardy
}

Department of

Medicine, Whiston

Hospital, Prescot,

Merseyside L35 5DR,

UK

S J McNulty

D Hutchinson

K J Hardy

Correspondence to:

Dr Steven McNulty,

Specialist Registrar in

General Internal Medicine,

Endocrinology and Diabetes,

University Hospital Aintree,

L9 7AL, UK

sid@doctors.org.uk

Submitted 25 January 2000 Accepted 4 April 2000
Longmoor Lane, Liverpool

\begin{abstract}
The aim of the study was to assess the extent to which published recommendations on the antithrombotic management of atrial fibrillation had been adopted into clinical practice in a busy district general hospital, and the impact of clinical audit on subsequent management. In the initial audit, 185 consecutive patients with atrial fibrillation were studied using their case notes to identify any further clinical risk factors for stroke. A management algorithm stratified patients with atrial fibrillation into high, moderate, or low risk of stroke according to the individual stroke risk factors. For patients at high risk, the
\end{abstract}

Atrial fibrillation and antithrombotic management

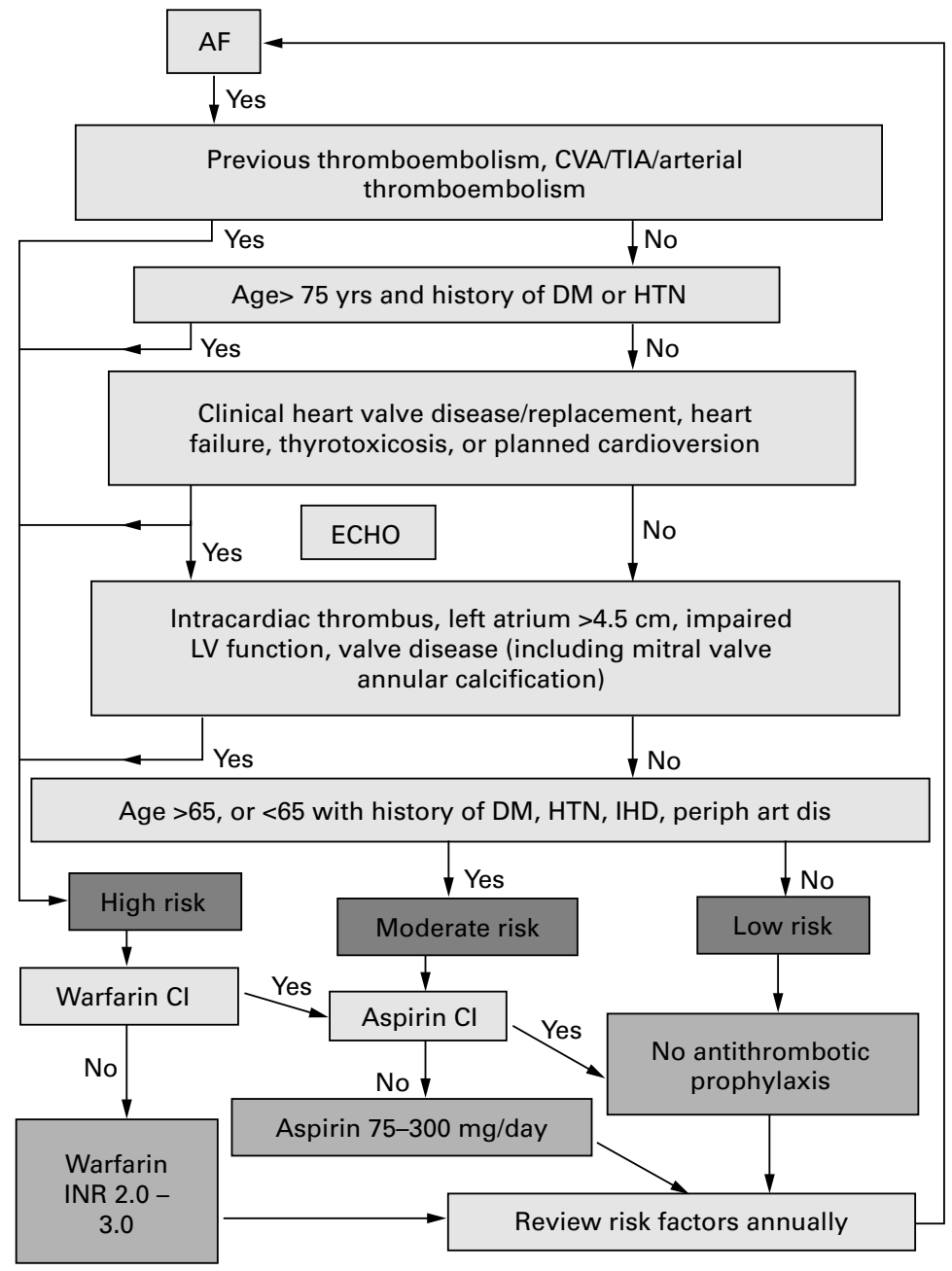

Figure 1 Antithrombotic management algorithm correct treatment is warfarin unless there are specific contraindications. For patients at moderate risk, the correct management is aspirin unless there are specific contraindications. Patients at low risk should receive no thromboprophylaxis. The clinical risks of stroke and thromboprophylaxis on discharge from hospital were recorded. An extensive education programme on stroke prevention in atrial fibrillation was undertaken. Six months later a further 185 consecutive patients with atrial fibrillation were audited. Overall, a large proportion (306/370; $83 \%$ ) of patients were at high risk of stroke. In the initial audit, antithrombotic management was correct in 89 patients $(48 \%)$. In the follow up audit, antithrombotic management was correct in 135 patients $(73 \%)(p<0.00001)$. If this improvement in management were extrapolated to all hospital patients in the United Kingdom, approximately 1400 strokes/ year could be avoided. Despite broad consensus in recent publications, antithrombotic management of atrial fibrillation remains imperfect, with many patients exposed to unnecessarily high risk of stroke.

(Postgrad Med f 2000;76:783-786)

Keywords: atrial fibrillation; anticoagulation

Atrial fibrillation is a major risk factor for thromboembolic stroke; $15-20 \%$ of all patients presenting with a stroke have this arrhythmia, ${ }^{12}$ and their mortality is 1.5 to 3 times greater than in stroke patients in sinus rhythm. ${ }^{2}$

The stroke risk in a patient with atrial fibrillation varies depending upon the concurrence of other risk factors for stroke. These include increasing age, valvar heart disease, previous stroke, transient ischaemic attacks or embolic events, left atrial enlargement, congestive heart failure or impaired left ventricular function, hypertension, ischaemic heart disease, and diabetes mellitus. It is the presence or absence of these additional risk factors that dictates absolute stroke risk in an individual with atrial fibrillation, and it is the balance of risk versus benefit that determines which thromboprophylactic measures should be used.

Large randomised prospective studies have established that antithrombotic drugs are effective in preventing stroke and reducing mortality in patients with atrial fibrillation..$^{3-7}$ Pooled analysis has shown that warfarin 
reduces annual incidence of stroke by $68 \%$ and stroke mortality by $33 \%$, with only minimal risk of major bleeding. ${ }^{8}$

Aspirin reduces stroke risk in patients with atrial fibrillation by $36 \%$. The combined outcome of stroke, systemic embolism, and death is reduced by $28 \%$ by aspirin in patients with atrial fibrillation. ${ }^{348}$ Despite this well publicised evidence, many patients with atrial fibrillation receive inadequate thromboprophylaxis. $^{9-11}$ The aim of the present study was to assess the extent to which published recommendations on antithrombotic management of atrial fibrillation had been adopted into clinical practice in the setting of a busy district general hospital, and the subsequent impact of clinical audit on thromboprophylaxis in atrial fibrillation.

\section{Methods}

We studied consecutive patients with atrial fibrillation admitted to St Helens and Knowsley Hospitals NHS Trust, a 1000 bed acute hospital trust with a catchment population of 334000 . In the initial audit, we identified 200 consecutive patients with ECG evidence of atrial fibrillation from cardiorespiratory department records. We undertook a retrospective case note audit in 185 of these patients, for whom case notes could be located. Using the algorithm proposed by Lip and Lowe in the British Medical fournal (fig 1), ${ }^{12}$ we stratified patients into high, moderate, or low risk of stroke (high risk, annual stroke incidence $8-12 \%$; moderate risk, $\sim 4 \%$; low risk, $\leqslant 1 \%$ ) and assessed whether they were receiving appropriate thromboprophylaxis on the basis of their individual risk of stroke and any documented contraindications to aspirin or warfarin treatment. Patients with atrial fibrillation were categorised as "high risk" for development of

Table 1 Characteristics of audit population

\begin{tabular}{llll}
\hline & $\begin{array}{l}\text { First audit } \\
(n=185)\end{array}$ & $\begin{array}{l}\text { Second } \\
\text { audit } \\
(n=185)\end{array}$ & $\begin{array}{l}\text { Overall } \\
(n=370)\end{array}$ \\
\hline Age in years (mean (SD)) & $73.9(11)$ & $76(11)$ & $75(11)$ \\
Male sex (\%) & $95(51)$ & $80(43)$ & $175(47)$ \\
High risk (\%) & $156(84)$ & $150(81)$ & $306(83)$ \\
Moderate risk (\%) & $23(12)$ & $35(19)$ & $58(16)$ \\
Low risk (\%) & $6(3)$ & 0 & $6(1)$ \\
\hline
\end{tabular}

Table 2 Antithrombotic management of high, moderate, and low risk patients

\begin{tabular}{|c|c|c|c|c|}
\hline Risk category & Treatment & Contraindications & $\begin{array}{l}\text { First audit } \\
(\%)\end{array}$ & $\begin{array}{l}\text { Second audit } \\
(\%)\end{array}$ \\
\hline High & $\begin{array}{l}\text { Warfarin } \\
\text { Aspirin } \\
\text { No thromboprophylaxis } \\
\text { Correct management }\end{array}$ & $\begin{array}{l}\text { No } \\
\text { Yes` } \\
\text { No } \\
\text { Yes` }\end{array}$ & $\begin{array}{l}59 / 156(38) \\
37 / 156(24) \\
5 / 156(3) \\
43 / 156(28) \\
12 / 156(8) \\
76 / 156(49)\end{array}$ & $\begin{array}{l}74 / 150(49) \ddagger \\
17 / 150(11) \oint \\
35 / 150(23) \oint \\
20 / 150(13) \ddagger \\
4 / 150(3) \dagger \\
113 / 150(72) \Phi\end{array}$ \\
\hline Moderate & $\begin{array}{l}\text { Warfarin } \\
\text { Aspirin }{ }^{\star} \\
\text { No thromboprophylaxis } \\
\text { Correct management }{ }^{\star}\end{array}$ & $\begin{array}{l}\text { No } \\
\text { Yes }^{\star}\end{array}$ & $\begin{array}{l}2 / 23(9) \\
8 / 23(35) \\
10 / 23(43) \\
3 / 23(13) \\
11 / 23(48)\end{array}$ & $\begin{array}{l}4 / 35(11) \dagger \\
18 / 35(51) \dagger \\
9 / 35(26) \dagger \\
4 / 35(11) \dagger \\
22 / 35(63) \dagger\end{array}$ \\
\hline Low & $\begin{array}{l}\text { Warfarin } \\
\text { Aspirin } \\
\text { No thromboprophylaxis }\end{array}$ & & $\begin{array}{l}2 / 6(33) \\
2 / 6(33) \\
2 / 6(33)\end{array}$ & $\begin{array}{l}0 / 0(0) \\
0 / 0(0) \\
0 / 0(0)\end{array}$ \\
\hline Overall & Correct management ${ }^{\star}$ & & $89 / 185(48)$ & $135 / 185(73)$ \\
\hline
\end{tabular}

${ }^{\star}$ Correct management, $\uparrow \mathrm{NS}, \neq \mathrm{p}<0.05, \S \mathrm{p}<0.0001 v$ first audit. stroke if any of the following comorbid conditions were present: previous ischaemic stroke or transient ischaemic attack, arterial thromboembolism, heart valve disease or replacement, clinical heart failure, thyrotoxicosis, planned cardioversion, age $>75$ years with a history of hypertension or diabetes, echocardiographic evidence of intracardiac thrombus, left atrium $>4.5 \mathrm{~cm}$ diameter, impaired left ventricular function, or valvar heart disease (including mitral valve annular calcification). Patients were categorised as "moderate risk" if aged $>65$ years, or $<65$ years with a history of diabetes, hypertension, ischaemic heart disease, or peripheral vascular disease. "Low risk" patients had none of the above comorbid conditions.

The initial audit findings were presented at multidisciplinary hospital meetings. Small tutorial groups consisting of preregistration house officers and senior house officers were arranged to specifically address the question of stroke thromboprophylaxis. Problem based learning was used in the tutorial groups, with a number of case scenarios presented to heighten familiarity with the algorithm. The algorithm was printed on the back of every ECG showing atrial fibrillation, and copies of it were posted prominently in the accident and emergency department, outpatient clinics, and on every ward and ward round trolley. Six months later the audit was repeated.

\section{STATISTICS}

Proportions were compared between groups using $2 \times 2$ contingency tables $\left(\chi^{2}\right)$. A significant value was taken as $\mathrm{p}<0.05$.

\section{Results}

We studied 370 patients with ECG confirmed atrial fibrillation, 185 in the first audit and 185 in the second audit. Patient demographics were not significantly different in the two audits (table 1).

\section{HIGH RISK GROUP}

This group made up 306 (83\%) of the patients studied in the two audits. The number and proportion of patients in the high risk category were similar in each audit: $156(84 \%)$ in the initial audit and $150(81 \%)$ in the second audit (table 2).

In the initial audit, 76 patients (47\%) with atrial fibrillation at high risk of stroke were managed correctly, compared with $113(75 \%)$ in the second audit $(\mathrm{p}<0.00001)$. Warfarin was prescribed correctly in 59 patients $(38 \%)$ in the initial audit and in $74(49 \%)$ in the second audit $(p=0.05)$. Aspirin was prescribed correctly in five patients $(3 \%)$ in the first audit and in $35(23 \%)$ in the second audit $(\mathrm{p}<0.0001)$, when allowing for the documented contraindication to warfarin. No thromboprophylaxis was given in 12 patients $(8 \%)$ in the initial audit and in four $(3 \%)$ in the second audit, when allowing for the documented contraindications to both warfarin and aspirin. 
Table 3 The difference in the number of strokes expected, comparing actual and ideal treatments, in the first and second audits

\begin{tabular}{|c|c|c|c|c|c|c|c|c|c|c|}
\hline \multirow[b]{2}{*}{ Risk of stroke } & \multirow{2}{*}{$\begin{array}{l}\text { Total No of } \\
\text { patients }\end{array}$} & \multicolumn{3}{|c|}{ Actual treatment } & \multirow{2}{*}{$\begin{array}{l}\text { Actual } \\
\text { expected } \\
\text { strokes }\end{array}$} & \multicolumn{3}{|c|}{ Ideal treatment } & \multirow{2}{*}{$\begin{array}{l}\text { Ideal } \\
\text { expected } \\
\text { strokes }\end{array}$} & \multirow{2}{*}{$\begin{array}{l}\text { Actual ideal } \\
\text { difference in } \\
\text { strokes }\end{array}$} \\
\hline & & Warfarin & Aspirin & None & & Warfarin & Aspirin & None & & \\
\hline \multicolumn{11}{|l|}{ First audit } \\
\hline High & 156 & 59 & 42 & 55 & 10.1 & 139 & 5 & 12 & 6.0 & 4.1 \\
\hline Moderate & 23 & 2 & 8 & 13 & 0.7 & 0 & 20 & 3 & 0.4 & 0.3 \\
\hline Low & 6 & 2 & 2 & 2 & 0 & 0 & 0 & 6 & 0 & 0 \\
\hline Total & & & & & 10.8 & & & & 6.4 & 4.4 \\
\hline \multicolumn{11}{|l|}{ Second audit } \\
\hline High & 150 & 74 & 52 & 24 & 8.1 & 111 & 35 & 4 & 6.3 & 1.9 \\
\hline Moderate & 35 & 4 & 18 & 13 & 0.8 & 0 & 31 & 4 & 0.6 & 0.2 \\
\hline Low & 0 & & & & 0 & & & & 0 & 0 \\
\hline Total & & & & & 8.9 & & & & 6.8 & 2.1 \\
\hline
\end{tabular}

Table 4 Comparison in morbidity and thrombotic stroke rate as a consequence of anticoagulant treatment per 1000 patients treated (first audit versus ideal)

\begin{tabular}{lclllll}
\hline First audit & Total & $\begin{array}{l}\text { Warfarin } \\
\text { treated }\end{array}$ & $\begin{array}{l}\text { Aspirin } \\
\text { treated }\end{array}$ & $\begin{array}{l}\text { Expected cerebral } \\
\text { haemorrhage }\end{array}$ & $\begin{array}{l}\text { Expected GI } \\
\text { haemorrhage }\end{array}$ & $\begin{array}{l}\text { Expected non-GI } \\
\text { haemorrhage }\end{array}$ \\
\hline "Ideal" morbidity & 1000 & 751 & 135 & 8 & 24 & 30 \\
Actual morbidity & 1000 & 340 & 281 & 4 & 15 & 14 \\
Difference in adverse events & 29 & & & 4 & 9 & 16 \\
\hline
\end{tabular}

GI, gastrointestinal.

MODERATE RISK GROUP

This group made up 58 (16\%) of the patients studied overall (table 2). There was no significant difference in the proportion of patients at moderate risk of stroke between the two audits: 23 patients $(12 \%)$ in the initial audit and 35 $(19 \%)$ in the second audit $(p=0.1)$. The correct management improved overall, although not significantly: 11 patients (48\%) in the initial audit and $22(63 \%)$ in the second audit. Aspirin was prescribed in eight patients $(35 \%)$ in the initial audit and in $18(51 \%)$ in the second audit.

There were three $(13 \%)$ and four $(11 \%)$ patients, respectively, from whom thromboprophylaxis was correctly withheld because of documented contraindications to aspirin. $\mathrm{Pa}-$ tients inappropriately denied thromboprophylaxis decreased, although not significantly, between the two audits: $10(43 \%)$ in the first and nine $(26 \%)$ in the second. There was no significant increase in the inappropriate prescribing of warfarin: two patients $(9 \%)$ in the initial audit and four (11\%) in the second audit.

LOW RISK GROUP

This group comprised only six patients overall $(1.5 \%)$ (table 2$)$. No low risk patients were seen in the second audit group.

STROKES SAVED

St Helens and Knowsley Hospitals NHS Trust admit 10000 medical emergencies a year, an average of 27 medical admissions a day. Ten per cent of all medical patients are in atrial fibrillation. ${ }^{13}$ This means that approximately 1000 patients with atrial fibrillation are being treated in our Trust yearly. Overall in our audit population, 306 patients $(83 \%)$ were at high risk of stroke, $58(16 \%)$ were at moderate risk of stroke, and six ( $1 \%$ ) were at low risk of stroke. Therefore in one year at our Trust, approximately 830 high risk patients, 160 moderate risk patients, and 10 low risk patients with atrial fibrillation would be seen. Patients at high risk of stroke and on no treatment have a
$10 \% /$ year stroke risk; those on aspirin treatment have a $6.4 \%$ year stroke risk (a $36 \%$ reduction in risk); and those on warfarin treatment have a 3.2\%/year stroke risk (a $68 \%$ reduction). Patients at moderate risk of stroke and on no treatment have a $4 \%$ year stroke risk, and aspirin treatment reduces this to $1.5 \% /$ year. ${ }^{8}$ It is therefore possible to calculate the number of strokes prevented annually if the improvements in management observed in our study were maintained. Comparing the two audit groups, the difference in treatment would result in 2.3 strokes being prevented per year of treatment for the 185 patients audited (table 3), equivalent to 13 strokes/1000 patients treated in one year.

The cost of the reduction in thrombotic stroke is increased morbidity secondary to aspirin and warfarin treatment. The expected frequency of major complications of aspirin and warfarin were calculated using data from a population based study in Rochester, Minnesota, USA. ${ }^{14}$

In that study, aspirin treatment during 576 patient-years of treatment resulted in 10 gastrointestinal haemorrhages, one intracranial haemorrhage, one non-gastrointestinal haemorrhage, and eight episodes of oesophagitis. There was one fatality in this group. Treatment with warfarin during 101 patient-years resulted in three gastrointestinal haemorrhages, one intracerebral haemorrhage, and four nongastrointestinal, non-cerebral haemorrhages. There were no fatalities in this group.

It is therefore possible to approximate our excess morbidity, comparing the two audit groups. In 1000 patients, there would be an excess of four cerebral, nine gastrointestinal, and 16 non-gastrointestinal haemorrhages (table 4). Thus the true saving in stroke overall would be $9 / 1000$ patients annually (the difference between thrombotic strokes prevented and cerebral haemorrhages occurring as a result of treatment). 


\section{Summary points}

- In a health district covering a population of about 350000 people, approximately 1000 medical referrals with atrial fibrillation would be expected each year

- The majority of patients with atrial fibrillation in our hospital based study were at high risk of stroke and, contraindications permitting, should receive warfarin.

- In our study the majority of patients were incorrectly managed with regard to thromboprophylaxis in the first audit.

- Simple education measures of hospital staff resulted in a significant improvement in thromboprophylaxis management which if sustained and extrapolated countrywide would result in 1400 strokes prevented annually.

\section{Discussion}

The evidence for thromboprophylaxis in atrial fibrillation is compelling and has received considerable attention in the medical journals. ${ }^{13815}$ In this study population most patients with atrial fibrillation (83\%) were at high risk of stroke. This is similar to the proportion of high risk patients identified in a previous study. ${ }^{16}$ Untreated, $8-12 \%$ of high risk patients will experience a stroke each year. ${ }^{72}$ In the absence of contraindications, these high risk patients should receive dose adjusted warfarin treatment to maintain the international normalised ratio (INR) between 2 and $3,,^{57}$ or possibly higher, ${ }^{3} 18$ which will reduce the annual incidence of stroke in these patients from $100 / 1000$ to $30 / 1000$ (absolute annual risk reduction of 70/1000). ${ }^{12}$ Most remaining patients with atrial fibrillation should receive aspirin thromboprophylaxis, which on average reduces annual stroke risk in these moderate risk patients from $40 / 1000$ to $15 / 1000$ (absolute annual risk reduction of 25/1000).${ }^{12}$ Only a minority of patients (those under 65 years of age, with no history of embolism, valvar heart disease, congestive cardiac failure, hypertension, or diabetes) are at such low thromboembolic risk that they require no thromboprophylaxis. ${ }^{12}$ In our trust population, this group accounted for only $1 \%$ of the population studied. The question, therefore, in hospital based practice is not whether thromboprophylaxis is required but which thromboprophylaxis to prescribe. Despite the known benefits of thromboprophylaxis in atrial fibrillation, our study suggests that in our acute hospital Trust this aspect of the management of atrial fibrillation is poor, with only $46 \%$ of patients receiving appropriate treatment. These results may represent a local problem, but other reports suggest that this is not the case. ${ }^{9-11}$ In the United Kingdom ${ }^{9}$ and other developed countries, ${ }^{10}{ }^{11}$ many patients with atrial fibrillation are being exposed to an unnecessarily high risk of stroke.
If our results can be generalised to the United Kingdom population of 55 million, 1400 strokes might be prevented annually. The median length of hospital stay after stroke in the Copenhagen stroke study was 27 days. ${ }^{19}$ An estimated direct cost of a stroke is $£ 23000$ (Professor J McMurray, personal communication). Thus at a conservative estimate 37800 bed-days and £32 million could be saved each year in the United Kingdom by preventing strokes with the appropriate thromboprophylactic management of atrial fibrillation. It is unlikely that increased treatment costs and costs arising from the small number of haemorrhagic complications of aspirin and warfarin would offset these savings to any great extent.

Our study shows that simple inexpensive measures can significantly improve atrial fibrillation thromboprophylaxis; however, the management could be improved even further, and we feel that both undergraduate and postgraduate medical education should highlight stroke prevention, with its potentially huge saving in patient morbidity and mortality throughout the United Kingdom.

We wish to thank Ms V Bannon and the clinical audit and cardiorespiratory departments at Whiston Hospital for their support.

1 Lowe GDO. Antithrombotic treatment and atrial fibrillation. BMf 1992;305:1445-6.

2 Sandercock P, Bramford J, Dennis M, et al. Atrial fibrillation and stroke: prevalence in different types of stroke and influence on early and long term prognosis (Oxfordshire community stroke project). BMF 1992;305:1460-5

3 Peterson P, Boysen G, Godtfredsen J, et al. Placebo controlled, randomised trial of warfarin and aspirin for the prevention of thromboembolic complications in chronic atrial fibrillation: The Copenhagen atrial fibrillation, aspirin, anticoagulation study. Lancet 1989;i:175-9.

4 Stroke prevention in atrial fibrillation investigators. Stroke prevention in atrial fibrillation study: final results. Circulation 1991;84:527-39.

5 Conolly SJ, Laupacis A, Gent M, et al. Canadian atrial fibrillation anticoagulation (CAFA) study. $\mathcal{F} \mathrm{Am}$ Coll Cardiol 1991;18:349-55.

6 Ezekowitz MD, Bridgers SL, James KE, et al. Warfarin in the prevention of stroke associated with non rheumatic atrial the prevention of stroke associated with non rhe

7 European atrial fibrillation trial study group. Secondary

European atrial fibrillation trial study group. Secondary
prevention in non rheumatic atrial fibrillation after transient prevention in non rheumatic atrial fibrillation after transient
ischaemic attack or major stroke. Lancet 1993;342:1255-62.

ischaemic attack or major stroke. Lancet 1993;342:1255-62.
8 Atrial fibrillation investigators. Risk factors for stroke and efficacy of antithrombotic therapy in atrial fibrillation. Arch Intern Med 1994;154:1449-57.

9 Lip GY, Tean KN, Dunn FG. Treatment of atrial fibrillation in a district general hospital. Br Heart fournal 1994;71:92-5.

10 Albers GW, Yim JM, Belen KM, et al. Status of antithrombotic therapy for patients with atrial fibrillation in university hospitals. Arch Intern Med 1996;156:2311-16.

11 Lawson F, McAlister F, Ackman M, et al. The utilisation of antithrombotic prophylaxis for atrial fibrillation in a geriatric rehabilitation hospital. F Am Geriatric Soc 1996;44:708-11.

12 Lip GYH, Lowe GDO. Antithrombotic treatment for atrial fibrillation. BMF 1996;312:45-9.

13 Stewart FM, Singh Y, Persson S, et al. Atrial fibrillation: prevalence and management in an acute medical unit. Aust NZ ₹ Med 1999;29:51-8.

14 Petty G, Brown R, Whisnant J, et al. Frequency of major complications of aspirin, warfarin and intravenous heparin for secondary stroke prevention. Ann Intern Med 1999;130: $14-22$

15 Lancaster T, Mant J, Singer DE. Stroke prevention in atrial fibrillation. BMF 1996;314:1563-4

16 Wolf PA, Abbott RD, Kannel WB. Atrial fibrillation: a major contributor to stroke in the elderly. The Framingham study. Arch Intern Med 1987;147:1561-4.

17 Rosendaal FR. The Scylla and Charybdis of oral anticoagulation treatment. $N$ Engl f Med 1996;335:587-9.

18 Stroke prevention in atrial fibrillation investigators. Warfarin versus aspirin for prevention of thromboembolism in atrial fibrillation: stroke prevention in atrial fibrillation II study. Lancet 1994;343:687-91.

19 Jorgensen HS, Nakayama H, Raaschou HO, et al. Acute stroke care and rehabilitation: an analysis of the direct cost and its clinical and social determinants. The Copenhagen stroke study. Stroke 1997;28:1138-41. 